\title{
Rare lung diseases II: Pulmonary alveolar proteinosis
}

\author{
Stephen C Juvet $\mathrm{MD}^{1}$, David Hwang MD PhD², Thomas K Waddell MD PhD ${ }^{3}$, Gregory P Downey MD ${ }^{1,4}$
}

\begin{abstract}
SC Juvet, D Hwang, TK Waddell, GP Downey. Rare lung diseases II: Pulmonary alveolar proteinosis. Can Respir J 2008;15(4):203-210.

The present article is the second in a series on rare lung diseases. It focuses on pulmonary alveolar proteinosis (PAP), a disorder in which lipoproteinaceous material accumulates in the alveolar space. PAP was first described in 1958, and for many years the nature of the material accumulating in the lungs was unknown. Major insights into PAP have been made in the past decade, and these have led to the notion that PAP is an autoimmume disorder in which autoantibodies interfere with signalling through the granulocyte-macrophage colony-stimulating factor receptor, leading to macrophage and neutrophil dysfunction. This has spurred new therapeutic approaches to this disorder. The discussion of PAP will begin with a case report, then will highlight the classification of PAP and review recent insights into the pathogenesis of PAP. The approach to therapy and the prognosis of PAP will also be discussed.
\end{abstract}

Key Words: Autoimmunity; GM-CSF; Growth factor; Respiratory failure; Restrictive lung disease

\section{CASE PRESENTATION}

A 46-year-old woman presented with a six-month history of progressive exertional dyspnea and fatigue. There was no history of fever, cough, weight loss, chest pain or peripheral edema. Her medical history included iron deficiency anemia that required parenteral iron replacement. She took no medications, except for iron replacements, and was a lifelong nonsmoker. She worked as a cashier, drank alcohol socially, had no known allergies, no pets and no history of recent travel.

On physical examination she appeared well, with no respiratory distress. The following parameters were recorded: blood pressure $110 / 65 \mathrm{mmHg}$, heart rate 78 beats/min, respiratory rate 20 breaths/min and body temperature $37.2^{\circ} \mathrm{C}$. Her arterial $\mathrm{O}_{2}$ saturation on room air was $91 \%$. Her jugular venous pressure was not elevated. Cardiac examination revealed normal first and second heart sounds, with no murmurs or extra sounds. Auscultation of the chest revealed scattered inspiratory crackles bilaterally. Her abdominal examination was unremarkable, without organomegaly, and there was no peripheral cyanosis, clubbing or edema.

Laboratory findings revealed a normal complete blood count and differential. Serum electrolytes, liver and renal function tests were all normal. Arterial blood gas analysis on room air revealed $\mathrm{pH}$ 7.37, partial pressure $(P)$ of $\mathrm{CO}_{2} 37 \mathrm{mmHg}, \mathrm{PO}_{2}$ $62 \mathrm{mmHg}$, and bicarbonate $24 \mathrm{mmol} / \mathrm{L}$. A chest radiograph demonstrated bilateral diffuse airspace opacities affecting both lungs (Figure 1). A computed tomography scan of the chest

\section{Les maladies pulmonaires rares II : La protéinose alvéolaire pulmonaire}

\begin{abstract}
Le présent article est le deuxième d'une série sur les maladies pulmonaires rares. Il porte sur la protéinose alvéolaire pulmonaire (PAP), un trouble qui provoque l'accumulation de substances lipoprotéinacées dans les espaces alvéolaires. La PAP a été décrite pour la première fois en 1958, et pendant de nombreuses années, la nature de la substance s'accumulant dans les poumons est demeurée inconnue. On a fait d'importantes observations sur la maladie depuis dix ans, lesquelles ont permis d'établir que la PAP est une maladie auto-immune qui provoque l'interférence des autoanticorps avec la signalisation par le récepteur des facteurs stimulant les colonies de granulocytes-macrophages, provoquant un dysfonctionnement des macrophages et des neutrophiles. Ce constat a suscité de nouvelles démarches thérapeutiques pour cette maladie. L'exposé sur la PAP commence par une étude de cas, puis porte sur la classification de la PAP et l'analyse des récentes observations sur la pathogénèse de la maladie. La démarche à l'égard du traitement et du pronostic de la PAP sera également abordée.
\end{abstract}

${ }^{1}$ Division of Respirology, Department of Medicine. ${ }^{2}$ Department of Laboratory Medicine an Toronto and the Toronto General Hospital of the University Health Network, Toronto, Ontario; ${ }^{4}$ Departments of Medicine, Pediatrics and Immunology, National Jewish Medical and Research Center and University of Colorado Denver, Denver, Colorado, USA

Correspondence: Dr Gregory P Downey, National Jewish Medical and Research Center, K701b, 1400 Jackson Street, Denver, Colorado 80206,

USA. Telephone 303-398-1436, fax 303-270-2243, e-mail downeyg@njc.org 


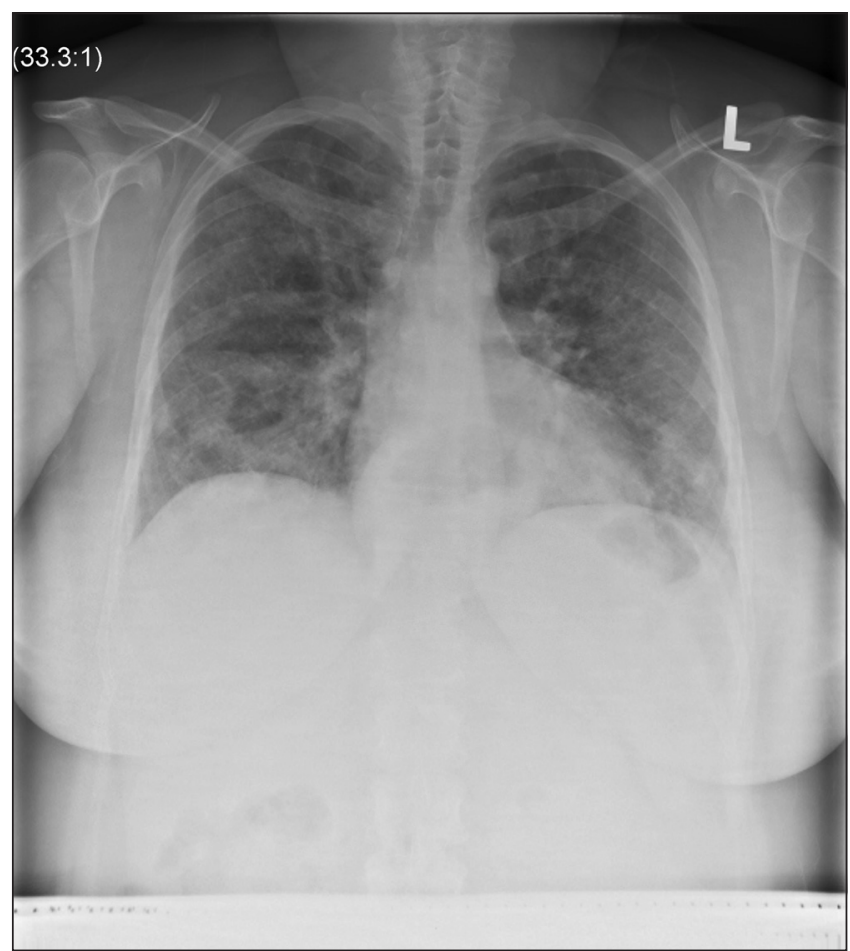

Figure 1) Posterior-anterior chest $x$-ray of a 46-year-old woman with alveolar proteinosis, characterized by bilateral perihilar alveolar infiltrates

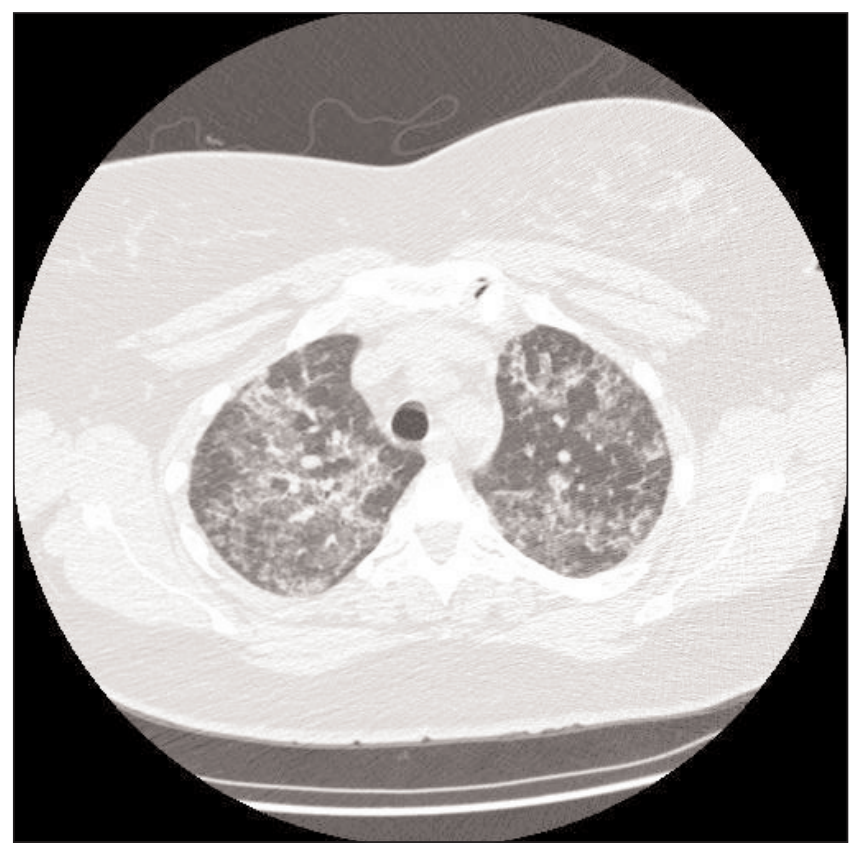

Figure 2) Chest computed tomography scan of the patient with alveolar proteinosis, illustrating bilateral ground glass alveolar infiltrates and interlobular septal thickening consistent with a 'crazy paving' pattern

alveolar compartment. It was first recognized as a distinct clinical entity in 1958 (1). There are three clinically recognized categories of PAP (2): idiopathic PAP, with onset occuring in adulthood; secondary PAP, also typically occurring in

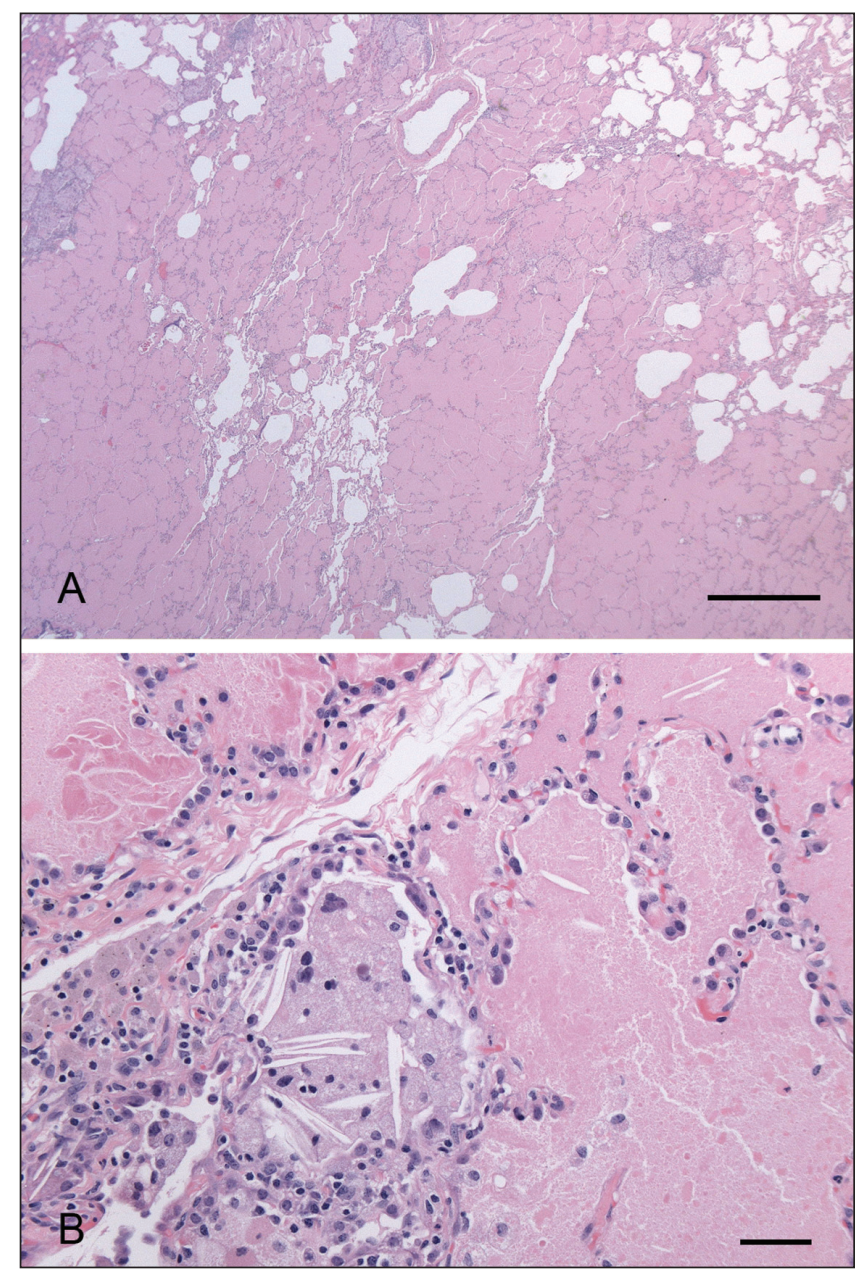

Figure 3) Open lung biopsy stained by hematoxylin and eosin, illustrating the eosinophilic foamy material present within the alveolar spaces. A The scale bar represents $1.0 \mathrm{~mm}$. B The scale bar represents $0.05 \mathrm{~mm}$

adulthood and resulting from another disorder or exposure; and congenital PAP, which occurs in the neonatal period, and causes severe respiratory distress.

Idiopathic PAP, the most common form of the disorder, is generally diagnosed in young to middle-aged adults, with a median age at diagnosis of 39 years (2). A recently published analysis (2) of 410 cases of PAP revealed that the median delay between symptom onset and diagnosis is seven months. The disorder is two to three times more common in men, and approximately $72 \%$ of patients are smokers (2). More than $90 \%$ of cases of PAP are classified as idiopathic $(1,3,4)$, with no identifiable familial or secondary etiology.

Patients with PAP report progressive exertional dyspnea, often associated with malaise and low-grade fever. However, prominent fevers should prompt an aggressive search for an underlying infection, as discussed in more detail below. Weight loss may be a clinical feature. A nonproductive cough and, occasionally, hemoptysis may occur.

On examination, patients with PAP usually do not exhibit any specific findings (2). Digital clubbing is uncommon; auscultation of the chest may reveal fine crackles, but is more frequently unrevealing. With these nonspecific symptoms, it is 
not surprising that many patients are misdiagnosed with chronic bronchitis. When chest radiography is performed, the radiographic findings are often strikingly more severe than would be expected based on the patient's history and physical examination.

When evaluating a patient with suspected PAP, care must be taken to consider possible exposure to environmental hazards that have been associated with secondary PAP. It should be noted, however, that many of these putatively causal exposures are only described in single case reports or small case series, and hence, direct evidence of causation is lacking. Examples of occupational exposures that have been associated with PAP include a variety of organic and inorganic dusts (flour, cement, wood) and fumes (chlorine gas, gasoline, plastics). Exposure to a heavy inhalational burden of silica has long been recognized to trigger acute 'silicoproteinosis' $(5,6)$, a condition that has many similarities to alveolar proteinosis, but this disorder is now uncommon in the era of workplace safety standards that mandate the use of personal protective equipment.

A variety of systemic disorders have been reported to be associated with PAP, and these cases are classified as secondary PAP. Most frequently, secondary PAP is reported in association with hematological disorders such as chronic myelogenous leukemia and myelodysplastic syndromes $(7,8)$. Altered immunity resulting from HIV infection (9), hypogammaglobulinemia (8), thymic alymphoplasia (10) and immunoglobulin (Ig) A deficiency (11) have all been associated with secondary PAP. The rare genetic disorder known as lysinuric protein intolerance, caused by a mutation in the $\mathrm{y}+\mathrm{L}$ amino acid transporter -1 gene $(12,13)$, leads to impaired membrane transport of dibasic amino acids. Its consequences include hematological abnormalities and secondary PAP $(14,15)$.

Congenital PAP, first described in 1981 (16), is a rare cause of neonatal respiratory distress syndrome. Clinically, such infants present with respiratory distress that is not responsive to surfactant or corticosteroid therapy. In such infants, lung transplantation is the only available life-saving therapy. As discussed further below, the pathogenesis of congenital PAP is quite distinct from that of PAP developing in adulthood.

\section{Biology and pathogenesis of PAP}

As described above, PAP of all types is characterized by the accumulation of surfactant-like material in the alveolar spaces. That the accumulated material in PAP may be a functional surfactant was first proposed in 1965 (17). In an elegant series of in vivo and in vitro experiments, Ramirez and Harlan (18) demonstrated in 1968 that the accumulation of phospholipids in the alveolar space in PAP was the result of decreased clearance, rather than of increased synthesis, of this material. They further demonstrated that the nature of the phospholipid in PAP is chemically similar (but not identical) to that of a naturally occurring surfactant. Although the latter assertion was initially challenged on the basis that the material isolated from the lungs of PAP patients lacked surface-active properties, subsequent studies have demonstrated that the material has bona fide surfactant properties (interested readers are referred to reference 2 for a review).

Alveolar macrophage dysfunction: The finding that surfactant clearance is impaired in PAP led to the hypothesis that PAP is the result of a defect in alveolar macrophage function. In the 1970s, several studies demonstrated that alveolar macrophages obtained from PAP patients by bronchoalveolar lavage (BAL) were phenotypically immature (19) and exhibited reduced ability to phagocytose Candida pseudotropicalis (19) and Staphylococcus aureus (20). These findings also supported the clinical observation that patients with PAP are predisposed to pulmonary infections. An early case series (21) appeared to support this latter hypothesis, describing an increased frequency of opportunistic infections in PAP patients. Many of the patients included in the studies in the present review, however, likely had secondary PAP related to an underlying hematological malignancy; many had also received immunosuppressive therapies, and it is therefore difficult to conclude from this evidence alone that PAP confers a predisposition to infection.

Unexpected insights from knockout mice - the role of GMCSF: In the 1970s and 1980s, intense interest in GM-CSF had developed in the field of experimental hematology. GM-CSF is a potent stimulator of myeloid hematopoiesis, and was cloned in 1984 (22). GM-CSF binds to a cell surface receptor that is comprised of a distinct alpha chain and a beta $(\beta)$ chain. The latter is also a component of the receptors for interleukin (IL)-3 and IL-5. Knockout mice lacking either the gene for GM-CSF itself $(23,24)$, or for the $\beta$ chain of the receptor $(25,26)$ were generated in the 1990s. To the surprise of the investigators, these mice did not have abnormal hematopoiesis, but instead reliably developed a pulmonary disorder indistinguishable from PAP. Furthermore, they also exhibited defective clearance of radiolabelled surfactant components, rather than increased surfactant synthesis, in keeping with the earlier observations made by Golde et al (19).

The GM-CSF receptor is expressed on type II pneumocytes and on alveolar macrophages $(27,28)$; pulmonary epithelial cells are a source of GM-CSF (27). Local intrapulmonary delivery of exogenous GM-CSF (29) or alveolar epithelial overexpression of GM-CSF (29) can correct the pulmonary pathology observed in GM-CSF-deficient mice. Notably, GMCSF-deficient mice also have other abnormalities, including a predisposition to infections $(30,31)$ and impaired macrophage function (32,33). Together, this series of investigations suggested that a GM-CSF deficiency in mice is a model that very closely resembles human PAP.

The link between GM-CSF and human idiopathic PAP was revealed when anti-GM-CSF antibodies were detected in the serum and BAL fluid of patients with the disease (34-36). This key finding explained the attenuated hematopoietic response observed in studies of GM-CSF used as a therapeutic agent for idiopathic PAP (37-39). Furthermore, the presence of antibodies that neutralize GM-CSF in patients with idiopathic PAP provides a pathogenetic explanation for the development of the disease in the absence of genetic abnormalities of GM-CSF or its receptor. Idiopathic PAP can therefore now be classified as an autoimmune disorder (2).

Why does the lack of GM-CSF, either due to its complete absence (in the knockout mouse) or to its binding by autoantibodies (in idiopathic PAP), lead to surfactant accumulation? The precise mechanism by which this occurs is not yet known, but it has been demonstrated that alveolar macrophages from GM-CSF-deficient mice exhibit decreased expression of PU.1, a transcription factor required for the functional maturation of these cells (40). These cells were unable to metabolize surfactant; however, when provided with GM-CSF in vitro, they expressed PU.1 and cell surface markers characteristic of mature macrophages, and acquired the 
ability to metabolize surfactant. PAP patients treated with GM-CSF had higher levels of PU.1 expression than healthy controls or PAP patients before treatment (41).

Additional signalling events downstream of the GM-CSF receptor also appear to be important for surfactant catabolism. Peroxisome proliferator-activated receptor-gamma (PPAR- $\gamma$ ) is activated by GM-CSF stimulation, which in turn activates the transcription of genes required to metabolize lipids and glucose. PPAR- $\gamma$ messenger RNA transcripts are absent in the alveolar macrophages of PAP patients, but are present in the alveolar macrophages of healthy control subjects (42). Moreover, GM-CSF therapy restores PPAR- $\gamma$ expression to control levels in patients with PAP (42).

Together, these animal and human observations illustrate the critical role of anti-GM-CSF autoantibodies in the pathogenesis of idiopathic PAP. They reveal the importance of GM-CSF in maintaining surfactant homeostasis in the alveolar microenvironment. Furthermore, they demonstrate that GM-CSF acts by driving the functional maturation of alveolar macrophages.

Infections associated with PAP: Although micro-organisms can be isolated from the lungs of PAP patients by BAL, many of these potential pathogens are rarely associated with clinical evidence of infection. For example, while the lung lavages of eight of 19 sequential patients treated between 1984 and 1992 grew nontuberculous mycobacteria, none of these patients manifest clinical evidence of disease related to infection from these organisms (43). In contrast, other investigators have observed an increased prevalence of disseminated opportunistic infections in patients with PAP. In particular, infection of the central nervous system by Aspergillus species (44) and Nocardia species (45-47) has been described. In Seymour and Presneill's 2002 review (2) of 410 cases of PAP, Nocardia species were isolated in 34 cases. They hypothesized that this observed increase in the frequency of disseminated and opportunistic infections may indicate a systemic defect in immunity in patients with PAP, although they did not detect any difference in neutrophil counts, corticosteroid use or cigarette smoking among patients with and without these infections (2).

A recent publication by Uchida et al (48) provided additional insight into the increased prevalence of infections observed in patients with PAP. The authors hypothesized that the presence of GM-CSF antibodies may also contribute to neutrophil dysfunction in patients with PAP, and in the GMCSF knockout mouse. Although neutrophil ultrastructure was normal, neutrophil phagocytic capacity was reduced, as were markers of neutrophil activation in response to GM-CSF stimulation. These deficiencies were observed both in mouse neutrophils and in neutrophils from patients with PAP, but not in those from healthy control subjects. Bacterial killing by neutrophils was also moderately diminished in both the mouse model and in patients with PAP, as compared with unaffected controls. Therefore, anti-GM-CSF antibodies appear to mediate functional impairment in both neutrophils and macrophages in PAP, which translates into a global but subtle defect in the innate immune response to bacterial infection.

As previously mentioned, secondary PAP has been described in the setting of HIV (9,49-52). However, this association is still restricted to case reports, and a direct pathogenetic relationship between HIV and secondary PAP has not been established. Some authors have suggested that Pneumocystis jirovecii pneumonia is responsible for these cases of PAP (50) and not
HIV infection per se. Moreover, the propensity for patients with either PAP (of any type) or HIV to present with opportunistic pulmonary infections such as those due to $P$ jirovecii and Nocardia asteroides could conceivably lead to a diagnostic dilemma. In the event of uncertainty, clinicians should consider ordering HIV serology to exclude this diagnosis.

Pathogenesis of congenital PAP: Deficiency of surfactant protein (SP)-B was reported in a patient with congenital PAP in 1993 (53). In fact, an inherited autosomal recessive mutation in the SP-B gene is the cause of this disorder in many cases (54). However, abnormalities in other proteins have been reported, such as the common $\beta$ chain of the IL-3, IL-5 and GM-CSF receptors (55), and in SP-C (56). It appears that congenital PAP can result from diverse genetic abnormalities, with many cases as yet unexplained (57).

\section{Physiological testing}

On pulmonary function testing, a restrictive ventilatory defect is usually apparent in PAP patients, with reductions in total lung capacity and vital capacity $(2,3)$. The diffusing capacity for carbon monoxide is often reduced out of proportion to the degree of the restrictive defect. Hypoxemia with an elevated alveolar-arterial $\mathrm{PO}_{2}$ gradient is the result. Arterial blood gas analysis often reveals compensated respiratory alkalosis (8). A markedly elevated shunt fraction while breathing $100 \% \mathrm{O}_{2}$ has been reported in PAP patients (58).

\section{Radiographic abnormalities}

In PAP, posteroanterior and lateral chest radiographs typically demonstrate bilateral and symmetrical airspace opacities that seem out of proportion to the relatively modest and indolent symptoms and clinical presentation. The opacities are generally most dense in the perihilar regions, and may exhibit a 'butterfly' configuration, similar to pulmonary edema or $P$ jirovecii pneumonia $(1,59)$. Other patterns may be seen, including focal infiltrates, reticular markings, nodules and asymmetrical infiltrates. Pleural effusions and lymphadenopathy are absent but, generally, the plain radiographic findings are nonspecific.

Computed tomography provides better visualization of the pulmonary parenchyma and illustrates the nature of the infiltrates. Again, however, opacities may be peripheral or central, focal or diffuse (60). Typically, ground glass opacities and increased interstitial markings are seen. Airspace opacities may be sharply demarcated from adjacent normal parenchyma in a nonanatomical fashion, creating a geographic appearance (60). The combination of interlobular septal thickening and ground glass opacification has been termed the 'crazy paving' appearance, due to its resemblance to cobblestones laid in an irregular, unpredictable fashion.

The crazy paving appearance was once believed to be pathognomonic for PAP, but has since been described in other conditions. Examples include bronchioloalveolar cell carcinoma, P jirovecii pneumonia, alveolar hemorrhage, sarcoidosis, cryptogenic organizing pneumonia and nonspecific interstitial pneumonia (61). Exogenous lipoid pneumonia and drug-induced lung diseases may also produce the same appearance (61). Given this broad differential diagnosis, a further careful diagnostic evaluation is required.

\section{Diagnosis of PAP}

Laboratory studies: Most routine laboratory studies are normal in patients with PAP. Serum lactate dehydrogenase may be 
elevated $(58,62)$, but this is a nonspecific finding. Similarly, elevated levels of SP-A, SP-B and SP-D have been reported in PAP $(63-66)$, but again, this finding is present in other disorders as well. Serum and BAL levels of the mucin-like protein KL-6 (67) are markedly elevated in PAP, and appear to correlate with disease activity. Overall, however, these laboratory indicators have not proven useful in making the diagnosis of PAP.

Anti-GM-CSF antibodies, as described above, are central to the pathogenesis of idiopathic PAP, and have shown promise as a diagnostic test. In the initial report by Kitamura et al (34), 11 idiopathic PAP patients, two secondary PAP patients, 53 healthy individuals and 14 patients with other lung diseases were examined. PAP was diagnosed by BAL and lung biopsy. BAL was performed in all of the patients and in 30 of the healthy subjects. Blood samples were obtained from 30 of the healthy subjects, five of the idiopathic PAP patients and one of the secondary PAP patients. The authors found that polyclonal anti-GM-CSF IgG antibodies were present in all serum and BAL fluid samples from idiopathic PAP patients, but were not present in the serum or BAL fluid of any of the other subjects, including those with secondary PAP. Furthermore, serum from the three patients with idiopathic PAP in remission (ie, no symptoms, clear chest radiograph) still contained the antibodies (34). Therefore, although this was a small study, it provides powerful evidence that IgG anti-GM-CSF antibodies drive the development of idiopathic PAP and may represent a useful diagnostic tool.

Bronchoalveolar lavage and lung biopsy: The diagnosis of PAP can be established definitively with BAL and/or lung biopsy. BAL fluid from patients with PAP is opaque and milky in appearance. When allowed to stand, the fluid spontaneously separates into a pale yellow, almost translucent supernatant and a thick sediment (8). A cytospin preparation demonstrates the presence of amorphous, granular, eosinophilic material. The enlarged alveolar macrophages obtained in this manner are characteristically vacuolated and foamy in appearance. Electron microscopy demonstrated the presence of tubular myelin, lamellar bodies and fused membrane structures within the amorphous extracellular material (3). These electron microscopical characteristics are morphologically the same as those of surfactant.

Open lung biopsy, traditionally considered to be the gold standard diagnostic test, is now largely unnecessary in the majority of cases of PAP; the combination of the clinical presentation, imaging findings and BAL results are generally sufficient to make the diagnosis (2). Biopsy specimens reveal multiple nodular areas of consolidation, with periodic acidSchiff stain-positive acellular material filling the alveoli and terminal bronchioles. There may be a mild associated lymphocytic infiltrate in the interstitium (1), but this feature is minor in comparison with the findings in the alveolar compartment. Importantly, the underlying architecture of the lung is usually preserved. In advanced cases, fibrotic changes may develop, which can lead to architectural distortion, although this is uncommon (68-70). As is the case with BAL samples, electron microscopy can be employed to examine the acellular material for the presence of tubular myelin in difficult cases.

\section{Therapy}

Treatment for idiopathic PAP has evolved from the use of a variety of nonspecific and largely ineffective agents, to the physical removal of the lipoproteinaceous material from the lungs, to the development of specific therapy targeted at the underlying pathogenesis of the disorder.

The first publication to describe PAP (1) also discussed its unsuccessful treatment with postural drainage, antibiotics and corticosteroids. Inhalation of aerosolized trypsin (71) and lavage with heparin and saline (72) have been reported to be helpful in isolated cases, as has the mucolytic agent ambroxol $(73,74)$. Overall, however, these therapies have not shown success in large numbers of patients (2), unlike WLL.

WLL: WLL has long been considered the definitive therapy for PAP. The idea that the accumulated material could be physically removed from the lungs of PAP patients was first advanced in the early 1960s, when selective segmental lavage was reported by Ramirez et al $(18,75)$. This was a trying experience for patients and physicians because it involved the transtracheal blind administration of warmed saline with only minimal analgesia, several times daily, for several weeks (76). However, in addition to providing the conceptual basis for the development of WLL, it represented the advent of the use of BAL as a therapeutic tool in modern pulmonary medicine.

WLL is now performed under general anesthesia, with a double-lumen endotracheal tube in place. The lungs are ventilated for $20 \mathrm{~min}$ with $100 \% \mathrm{O}_{2}$ to wash out nitrogen. The lung to be treated is then isolated at end-expiration, and the volume of that lung is estimated from the preoperative functional residual capacity. Warmed $0.9 \%$ saline is then instilled at a rate of $100 \mathrm{~mL} / \mathrm{min}$, which approximates the rate of absorption of the $100 \% \mathrm{O}_{2}$ from the lung. Once the functional residual capacity has been replaced with saline, tidal volume-sized aliquots of saline are instilled under gravitational force and then allowed to drain out. The procedure is repeated, often using $10 \mathrm{~L}$ to $12 \mathrm{~L}$ of saline per lung, until the effluent, which is typically initially milky and turbid, becomes clear (77). Once this occurs, residual fluid is aspirated and the lung is ventilated with $100 \% \mathrm{O}_{2}$ again. A decision can then be made whether to proceed to WLL of the contralateral lung (77). Chest percussion is commonly included in the procedure to promote clearance of the lipoproteinaceous material (78). The WLL procedure takes $2 \mathrm{~h}$ to $4 \mathrm{~h}$ and should be performed in a centre with anesthesiologists skilled in the placement and management of double-lumen endotracheal tubes. Care must be taken to avoid barotrauma. Saline thorax is another potential complication; insertion of a chest tube is occasionally required. Diuresis is forced during the procedure and for several days afterward to ensure resorption of all excess extravascular lung water. In severely hypoxic patients with PAP, WLL has been performed with extracorporeal membrane oxygenation and in hyperbaric chambers $(79,80)$.

Because no prospective studies of WLL are available, it is difficult to determine the effect of this procedure on prognosis. However, the vast majority of cases of idiopathic PAP have been reported to improve on clinical, radiographic and physiological grounds following WLL (2). Improvement in $\mathrm{PO}_{2}$, forced vital capacity, total lung capacity and diffusing capacity for carbon monoxide is expected for several days following the procedure (81). The goal of therapy is a return to normal functioning, with freedom from symptoms such as exertional dyspnea (77). The median duration of freedom from recurrent symptoms appears to be approximately 15 months, but is highly variable, with many patients needing only a single lavage (2). A small number of patients do not respond to WLL, and 
younger age appears to be the major predictor of a poor response. Nonresponders had a similar long-term prognosis to responders, save for slightly decreased survival (87\% $\pm 9 \%$ versus $97 \% \pm 2 \%$ ) in these patients in the first six months after WLL (2). It should be noted that congenital PAP appears to be particularly unlikely to respond to WLL (2).

GM-CSF therapy for idiopathic PAP: The discovery that GM-CSF-deficient mice develop a disorder resembling PAP, which resolves when GM-CSF is replaced, led to the hypothesis that GM-CSF therapy could be effective in humans with the disorder. The first prospective study of GM-CSF therapy in PAP patients began in 1995. Fourteen patients with idiopathic PAP were treated with $5 \mu \mathrm{g} / \mathrm{kg} /$ day of GM-CSF given subcutaneously. Five patients (36\%) responded, as judged by improvements in the alveolar-arterial gradient for $\mathrm{O}_{2}$; a sixth patient responded following an escalation of the dose to $20 \mu \mathrm{g} / \mathrm{kg} /$ day (38). The remaining eight patients did not respond to GMCSF. All patients had anti-GM-CSF antibodies in serum obtained before the initiation of therapy. A second study, using a dosage of $5 \mu \mathrm{g} / \mathrm{kg} /$ day to $9 \mu \mathrm{g} / \mathrm{kg} /$ day, reported significant clinical, radiographic and physiological improvements in five of seven patients, including improvements in the alveolar-arterial gradient $(82,83)$. Benefits are generally not seen for eight to 12 weeks (83). Interestingly, the hematopoietic response to GM-CSF is blunted, which appears to result from the presence of anti-GM-CSF antibodies $(38,83)$. In summary, although GM-CSF is generally well tolerated, the overall response rate to this therapy in these two small, nonrandomized studies appears to be less than $50 \%$, which is in stark contrast to the ability of WLL to produce rapid improvements in symptoms and pulmonary function in the majority of patients. There are reports of the successful use of inhaled GM-CSF for the treatment of PAP. Further studies of GM-CSF therapy in idiopathic PAP are clearly warranted to better define its role.

Treatment of secondary PAP: If secondary PAP is diagnosed, the underlying disorder must be treated, or the patient should be removed from exposure to the suspected environmental agent. Additional treatment with WLL may still be necessary, and has been performed successfully, in secondary PAP (84-86). Because secondary PAP is not associated with anti-GM-CSF antibodies, there is no rationale for GM-CSF in its treatment.

Treatment for congenital PAP: As with secondary PAP, GM-CSF therapy should not be used for congenital PAP, which is the result of SP-B deficiency or a mutation in the $\beta$ chain of the GM-CSF receptor (and perhaps other unrecognized mutations). Unfortunately, congenital PAP does not respond well to WLL (2). At the present time, lung transplantation appears to be the only therapeutic option in cases of congenital PAP.

\section{Prognosis}

The prognosis in idiopathic PAP is considerably better than might be expected, based on the severity of physiological derangements that can arise in this condition. Actuarial fiveand 10-year overall survival rates are approximately $75 \%$ and $68 \%$, respectively (2). Disease-specific survival is higher; approximately $88 \%$ at five years (2). The only specific adverse prognostic factor identified is age, with patients younger than five years (many of whom likely had congenital PAP) having an actuarial survival of only $14 \%$ at five years after diagnosis. Patients older than the median age at diagnosis (39 years) were at higher risk of death than younger patients, but not for diseasespecific mortality (2). Although smokers are at increased risk for the development of PAP, continued smoking did not appear to influence survival (2). Overall, the risk of death from respiratory failure appears to be approximately $10 \%$ to $15 \%$ (2).

Spontaneous improvement, or rarely, complete resolution, occurs in a minority of idiopathic PAP patients. In their review of all reported cases of PAP to 2002 (2), Seymour and Presneill reported that $7.9 \%$ exhibited some spontaneous improvement. That such improvement may occur has been recognized since PAP was first described, with five of the original 26 patients reported by Rosen and colleagues (1) demonstrating "definite improvement". It should be noted that radiographic or physiological improvements are often incomplete (2).

Pulmonary fibrosis has occurred rarely in PAP, typically late in the course of the disease $(69,70)$. Its clinical and prognostic significance is unclear, but its presence would be expected to result in incompletely reversible physiological abnormalities. Whether the pulmonary fibrosis resulting from PAP is progressive is unclear.

\section{CONCLUSIONS}

Like lymphangioleiomyomatosis, PAP is a disease in which significant conceptual and therapeutic advances have been made as a result of investigations into the fundamental biological aberrations that characterize the disorder. The serendipitous discovery of PAP-like disease in the GM-CSF-deficient mouse, and the subsequent finding of anti-GM-CSF antibodies in idiopathic PAP patients, has recast it as an autoimmune disorder.

Despite these advances, numerous challenges remain. Much about the biology of idiopathic PAP is still incompletely understood. For example, what is the role of cigarette smoking in the pathogenesis of PAP? What is the significance of the interstitial lymphocytic infiltrate that accompanies PAP? Although the evidence strongly implicates anti-GMCSF antibodies in the pathogenesis of the disease, what triggers their synthesis in individual patients and what factors are responsible for the waxing and waning course in some patients?

Therapy for PAP is also an area that merits further investigation. What is the effect of treatment on the natural history of the disease? WLL effectively treats PAP in most instances, but it is cumbersome and associated with both morbidity and mortality. A treatment that can be administered by the patient is conceptually much more appealing. However, although GMCSF can be used, its 50\% success rate and expense makes it suboptimal. Clearly, more research needs to be done to understand why some patients respond and others do not.

Alternative therapeutic approaches are also worth considering. Given that idiopathic PAP results from the presence of an autoantibody, B cell-specific treatments may be useful. Rituximab, a monoclonal antibody directed at the CD20 molecule expressed on the surface of mature B cells, was originally employed in the treatment of non-Hodgkin B cell lymphomas, but has shown efficacy in a variety of autoimmune diseases (87). Conceivably, this agent, or a similar one, may be useful in the treatment of PAP. Similarly, it may be possible to deliver high concentrations of GM-CSF to the alveolar space to overwhelm anti-GM-CSF antibodies at their site of action. Aerosolized GM-CSF has been used successfully in PAP, and it may be possible to induce alveolar epithelial overexpression of GM-CSF using gene therapy, as 
has been achieved in animal models $(29,88)$. Congenital PAP, while rare, is a devastating illness that has a completely different pathogenesis. Deficiency of SP-B or the $\beta$ chain of the GM-CSF receptor could also theoretically be replaced using genetic or cellular therapies directed at the alveolar compartment.

\section{REFERENCES}

1. Rosen SH, Castleman B, Liebow AA. Pulmonary alveolar proteinosis. N Engl J Med 1958;258:1123-42.

2. Seymour JF, Presneill JJ. Pulmonary alveolar proteinosis: Progress in the first 44 years. Am J Respir Crit Care Med 2002;166:215-35.

3. Prakash UB, Barham SS, Carpenter HA, Dines DE, Marsh HM. Pulmonary alveolar phospholipoproteinosis: Experience with 34 cases and a review. Mayo Clin Proc 1987;62:499-518.

4. Goldstein LS, Kavuru MS, Curtis-McCarthy P, Christie HA, Farver C, Stoller JK. Pulmonary alveolar proteinosis: Clinical features and outcomes. Chest 1998;114:1357-62.

5. Ziskind M, Jones RN, Weill H. Silicosis. Am Rev Respir Dis 1976;113:643-65.

6. Xipell JM, Ham KN, Price CG, Thomas DP. Acute silicoproteinosis. Thorax 1977;32:104-11.

7. Cordonnier C, Fleury-Feith J, Escudier E, Atassi K, Bernaudin JF. Secondary alveolar proteinosis is a reversible cause of respiratory failure in leukemic patients. Am J Respir Crit Care Med 1994;149:788-94.

8. Kavuru M, Bonfield TL, Thomassen MJ. Pulmonary alveolar proteinosis. In: RJ Mason, Courtney Broaddus V, Murray JF, Nadel JA. Textbook of Respiratory Medicine. Philadelphia: Saunders, 2005:1716-34.

9. Israel RH, Magnussen CR. Are AIDS patients at risk for pulmonary alveolar proteinosis? Chest 1989;96:641-2.

10. Haworth JC, Hoogstraten J, Taylor H. Thymic alymphoplasia. Arch Dis Child 1967;42:40-54.

11. Webster JR Jr, Battifora H, Furey C, Harrison RA, Shapiro B. Pulmonary alveolar proteinosis in two siblings with decreased immunoglobulin A. Am J Med 1980;69:786-9.

12. Borsani G, Bassi MT, Sperandeo MP, et al. SLC7A7, encoding a putative permease-related protein, is mutated in patients with lysinuric protein intolerance. Nat Genet 1999;21:297-301.

13. Torrents D, Mykkänen J, Pineda M, et al. Identification of SLC7A7, encoding y+LAT-1, as the lysinuric protein intolerance gene. Nat Genet 1999;21:293-6.

14. Santamaria F, Parenti G, Guidi G, et al. Early detection of lung involvement in lysinuric protein intolerance: Role of highresolution computed tomography and radioisotopic methods. Am J Respir Crit Care Med 1996;153:731-5.

15. Parenti G, Sebastio G, Strisciuglio P, et al. Lysinuric protein intolerance characterized by bone marrow abnormalities and severe clinical course. J Pediatr 1995;126:246-51.

16. Teja K, Cooper PH, Squires JE, Schnatterly PT. Pulmonary alveolar proteinosis in four siblings. N Engl J Med 1981;305:1390-2.

17. Larson RK, Gordinier R. Pulmonary alveolar proteinosis. Report of six cases, review of the literature, and formulation of a new theory. Ann Intern Med 1965;62:292-312.

18. Ramirez J, Harlan WR Jr. Pulmonary alveolar proteinosis. Nature and origin of alveolar lipid. Am J Med 1968;45:502-12.

19. Golde DW, Territo M, Finley TN, Cline MJ. Defective lung macrophages in pulmonary alveolar proteinosis. Ann Intern Med 1976;85:304-9.

20. Harris JO. Pulmonary alveolar proteinosis: Abnormal in vitro function of alveolar macrophages. Chest 1979;76:156-9.

21. Bedrossian CW, Luna MA, Conklin RH, Miller WC. Alveolar proteinosis as a consequence of immunosuppression. A hypothesis based on clinical and pathologic observations. Hum Pathol 1980;11(5 Suppl):527-35.

22. Gough NM, Gough J, Metcalf D, et al. Molecular cloning of cDNA encoding a murine haematopoietic growth regulator, granulocytemacrophage colony stimulating factor. Nature 1984;309:763-7.

23. Stanley E, Lieschke GJ, Grail D, et al. Granulocyte/macrophage colony-stimulating factor-deficient mice show no major perturbation of hematopoiesis but develop a characteristic pulmonary pathology. Proc Natl Acad Sci USA 1994;91:5592-6.
With our improved understanding of the various forms of PAP, it is hoped that further advances in therapy are forthcoming. Increased understanding of PAP with the use of careful and well-designed in vitro, animal and human studies will hopefully also stimulate further research into the mechanisms of other unusual and more common lung diseases.

24. Dranoff G, Crawford AD, Sadelain M, et al. Involvement of granulocyte-macrophage colony-stimulating factor in pulmonary homeostasis. Science 1994;264:713-6.

25. Ikegami M, Ueda T, Hull W, et al. Surfactant metabolism in transgenic mice after granulocyte macrophage-colony stimulating factor ablation. Am J Physiol 1996;270:L650-8.

26. Nishinakamura R, Nakayama N, Hirabayashi Y, et al. Mice deficient for the IL-3/GM-CSF/IL-5 beta c receptor exhibit lung pathology and impaired immune response, while beta IL3 receptordeficient mice are normal. Immunity 1995;2:211-22.

27. Trapnell BC, Whitsett JA. Gm-CSF regulates pulmonary surfactant homeostasis and alveolar macrophage-mediated innate host defense. Annu Rev Physiol 2002;64:775-802.

28. Huffman Reed JA, Rice WR, Zsengellér ZK, Wert SE, Dranoff G, Whitsett JA. GM-CSF enhances lung growth and causes alveolar type II epithelial cell hyperplasia in transgenic mice. Am J Physiol 1997;273:L715-25

29. Zsengellér ZK, Reed JA, Bachurski CJ, et al. Adenovirus-mediated granulocyte-macrophage colony-stimulating factor improves lung pathology of pulmonary alveolar proteinosis in granulocytemacrophage colony-stimulating factor-deficient mice. Hum Gene Ther 1998;9:2101-9.

30. Zhan Y, Lieschke GJ, Grail D, Dunn AR, Cheers C. Essential roles for granulocyte-macrophage colony-stimulating factor (GM-CSF) and G-CSF in the sustained hematopoietic response of Listeria monocytogenes-infected mice. Blood 1998;91:863-9.

31. Seymour JF, Lieschke GJ, Grail D, Quilici C, Hodgson G, Dunn AR. Mice lacking both granulocyte colony-stimulating factor (CSF) and granulocyte-macrophage CSF have impaired reproductive capacity, perturbed neonatal granulopoiesis, lung disease, amyloidosis, and reduced long-term survival. Blood 1997;90:3037-49.

32. Scott CL, et al. Mice unresponsive to GM-CSF are unexpectedly resistant to cutaneous Leishmania major infection. Microbes Infect 2000;2:1131-8

33. Zhan Y, Basu S, Lieschke GJ, Grail D, Dunn AR, Cheers C. Functional deficiencies of peritoneal cells from gene-targeted mice lacking G-CSF or GM-CSF. J Leukoc Biol 1999;65:256-64.

34. Kitamura T, Tanaka N, Watanabe J, et al. Idiopathic pulmonary alveolar proteinosis as an autoimmune disease with neutralizing antibody against granulocyte/macrophage colony-stimulating factor. J Exp Med 1999;190:875-80.

35. Kitamura T, Uchida K, Tanaka N, et al. Serological diagnosis of idiopathic pulmonary alveolar proteinosis. Am J Respir Crit Care Med 2000;162:658-62.

36. Tanaka N, Watanabe J, Kitamura T, Yamada Y, Kanegasaki S, Nakata K. Lungs of patients with idiopathic pulmonary alveolar proteinosis express a factor which neutralizes granulocytemacrophage colony stimulating factor. FEBS Lett 1999;442:246-50.

37. Seymour JF, Begley CG, Dirksen U, et al. Attenuated hematopoietic response to granulocyte-macrophage colonystimulating factor in patients with acquired pulmonary alveolar proteinosis. Blood 1998;92:2657-67.

38. Seymour JF, Presneill JJ, Schoch OD, et al. Therapeutic efficacy of granulocyte-macrophage colony-stimulating factor in patients with idiopathic acquired alveolar proteinosis. Am J Respir Crit Care Med 2001;163:524-31.

39. Seymour JF, Dunn AR, Vincent JM, Presneill JJ, Pain MC. Efficacy of granulocyte-macrophage colony-stimulating factor in acquired alveolar proteinosis. N Engl J Med 1996;335:1924-5.

40. Shibata Y, Berclaz PY, Chroneos ZC, Yoshida M, Whitsett JA, Trapnell BC. GM-CSF regulates alveolar macrophage differentiation and innate immunity in the lung through PU.1. Immunity 2001;15:557-67.

41. Bonfield TL, Raychaudhuri B, Malur A, et al. PU.1 regulation of human alveolar macrophage differentiation requires 
granulocyte-macrophage colony-stimulating factor.

Am J Physiol Lung Cell Mol Physiol 2003;285:L1132-6.

42. Bonfield TL, Farver CF, Barna BP, et al. Peroxisome proliferatoractivated receptor-gamma is deficient in alveolar macrophages from patients with alveolar proteinosis. Am J Respir Cell Mol Biol 2003;29:677-82.

43. Witty LA, Tapson VF, Piantadosi CA. Isolation of mycobacteria in patients with pulmonary alveolar proteinosis. Medicine (Baltimore) 1994;73:103-9.

44. Björkholm B, Elgefors B. Cerebellar aspergilloma. Scand J Infect Dis 1986;18:375-8.

45. Taleghani-Far M, Barber JB, Sampson C, Harden KA. Cerebral nocardiosis and alveolar proteinosis. Am Rev Respir Dis 1964;89:561-5.

46. Wongthim S, Charoenlap P, Udompanich V, Punthumchinda K, Suwanagool P. Pulmonary nocardiosis in Chulalongkorn Hospital. J Med Assoc Thai 1991;74:271-7.

47. Oerlemans WG, Jansen EN, Prevo RL, Eijsvogel MM. Primary cerebellar nocardiosis and alveolar proteinosis. Acta Neurol Scand 1998;97:138-41.

48. Uchida K, Beck DC, Yamamoto T, et al. GM-CSF autoantibodies and neutrophil dysfunction in pulmonary alveolar proteinosis. N Engl J Med 2007;356:567-79.

49. Ruben FL, Talamo TS. Secondary pulmonary alveolar proteinosis occurring in two patients with acquired immune deficiency syndrome. Am J Med 1986;80:1187-90.

50. Tran Van Nhieu J, Vojtek AM, Bernaudin JF, Escudier E, Fleury-Feith J. Pulmonary alveolar proteinosis associated with Pneumocystis carinii. Ultrastructural identification in bronchoalveolar lavage in AIDS and immunocompromised non-AIDS patients. Chest 1990;98:801-5.

51. Nachajon RV, Rutstein RM, Rudy BJ, Collins MH. Pulmonary alveolar proteinosis in an HIV-infected child. Pediatr Pulmonol 1997;24:292-5.

52. Conces DJ Jr, Tarver RD. Noninfectious and nonmalignant pulmonary disease in AIDS. J Thorac Imaging 1991;6:53-9.

53. Nogee LM, de Mello DE, Dehner LP, Colten HR. Brief report: Deficiency of pulmonary surfactant protein B in congenital alveolar proteinosis. N Engl J Med 1993;328:406-10.

54. Nogee LM, Garnier G, Dietz HC, et al. A mutation in the surfactant protein B gene responsible for fatal neonatal respiratory disease in multiple kindreds. J Clin Invest 1994;93:1860-3.

55. Dirksen U, Nishinakamura R, Groneck P, et al. Human pulmonary alveolar proteinosis associated with a defect in GM-CSF/IL-3/IL-5 receptor common beta chain expression. J Clin Invest 1997;100:2211-7.

56. Tredano M, Griese M, Brasch F, et al. Mutation of SFTPC in infantile pulmonary alveolar proteinosis with or without fibrosing lung disease. Am J Med Genet A 2004;126:18-26.

57. Latzin P, Tredano M, Wüst Y, et al. Anti-GM-CSF antibodies in paediatric pulmonary alveolar proteinosis. Thorax 2005;60:39-44.

58. Martin RJ, Rogers RM, Myers NM. Pulmonary alveolar proteinosis: Shunt fraction and lactic acid dehydrogenase concentration as aids to diagnosis. Am Rev Respir Dis 1978;117:1059-62.

59. Mazzone P, Thomassen MJ, Kavuru M. Our new understanding of pulmonary alveolar proteinosis: What an internist needs to know. Cleve Clin J Med 2001;68:977-8, 981-2, 984-5 passim.

60. Godwin JD, Müller NL, Takasugi JE. Pulmonary alveolar proteinosis: CT findings. Radiology 1988;169:609-13.

61. Rossi SE, Erasmus JJ, Volpacchio M, Franquet T, Castiglioni T, McAdams HP. "Crazy-paving" pattern at thin-section CT of the lungs: Radiologic-pathologic overview. Radiographics 2003;23:1509-19.

62. Hoffman RM, Rogers RM. Serum and lavage lactate dehydrogenase isoenzymes in pulmonary alveolar proteinosis. Am Rev Respir Dis $1991 ; 143: 42-6$.

63. Seymour JF, Doyle IR, Nakata K, et al. Relationship of anti-GMCSF antibody concentration, surfactant protein A and B levels, and serum LDH to pulmonary parameters and response to GM-CSF therapy in patients with idiopathic alveolar proteinosis. Thorax 2003;58:252-7.

64. Doyle IR, Davidson KG, Barr HA, Nicholas TE, Payne K, Pfitzner J. Quantity and structure of surfactant proteins vary among patients with alveolar proteinosis. Am J Respir Crit Care Med 1998;157:658-64.

65. Brasch F, Birzele J, Ochs M, et al. Surfactant proteins in pulmonary alveolar proteinosis in adults. Eur Respir J 2004;24:426-35.

66. Kuroki Y, Tsutahara S, Shijubo N, et al. Elevated levels of lung surfactant protein $A$ in sera from patients with idiopathic pulmonary fibrosis and pulmonary alveolar proteinosis. Am Rev Respir Dis 1993;147:723-9.

67. Takahashi T, Munakata M, Suzuki I, Kawakami Y. Serum and bronchoalveolar fluid KL-6 levels in patients with pulmonary alveolar proteinosis. Am J Respir Crit Care Med 1998;158:1294-8.

68. Kaplan AI, Sabin S. Case report: Interstitial fibrosis after uncomplicated pulmonary alveolar proteinosis. Postgrad Med $1977 ; 61: 263,265$

69. Clague HW, Wallace AC, Morgan WK. Pulmonary interstitial fibrosis associated with alveolar proteinosis. Thorax 1983;38:865-6.

70. Hudson AR, Halprin GM, Miller JA, Kilburn KH. Pulmonary interstitial fibrosis following alveolar proteinosis. Chest 1974;65:700-2.

71. Arora PL, Rogers RM, Mayock RL. Alveolar proteinosis. Experience with trypsin therapy. Am J Med 1968;44:889-99.

72. Sunderland WA, Klein RL. Heparin absorption during heparinsaline lung lavage in a patient with pulmonary alveolar proteinosis. Chest 1973;63:1033-4

73. Hashizume T. Pulmonary alveolar proteinosis successfully treated with ambroxol. Intern Med 2002;41:1175-8.

74. Diaz JP, Manresa Presas F, Benasco C, Guardiola J, Munoz L, Clariana A. Response to surfactant activator (ambroxol) in alveolar proteinosis. Lancet 1984;1:1023.

75. Ramirez J, Campbell GD. Pulmonary alveolar proteinosis. Endobronchial treatment. Ann Intern Med 1965;63:429-41.

76. Ramírez-Rivera J. The strange beginnings of diagnostic and therapeutic bronchoalveolar lavage. P R Health Sci J 1992;11:27-32.

77. Shah PL, Hansell D, Lawson PR, Reid KB, Morgan C. Pulmonary alveolar proteinosis: Clinical aspects and current concepts on pathogenesis. Thorax 2000;55:67-77.

78. Hammon WE, McCaffree DR, Cucchiara AJ. A comparison of manual to mechanical chest percussion for clearance of alveolar material in patients with pulmonary alveolar proteinosis (phospholipidosis). Chest 1993;103:1409-12.

79. Altose MD, Hicks RE, Edwards MW Jr. Extracorporeal membrane oxygenation during bronchopulmonary lavage. Arch Surg 1976;111:1149-53.

80. Cohen ES, Elpern E, Silver MR. Pulmonary alveolar proteinosis causing severe hypoxemic respiratory failure treated with sequential whole-lung lavage utilizing venovenous extracorporeal membrane oxygenation: A case report and review. Chest 2001;120:1024-6.

81. Rogers RM, Levin DC, Gray BA, Moseley LW Jr. Physiologic effects of bronchopulmonary lavage in alveolar proteinosis. Am Rev Respir Dis 1978;118:255-64.

82. Mazzone PJ, et al. Granulocyte-macrophage colony-stimulating factor therapy for pulmonary alveolar proteinosis. Am J Respir Crit Care Med 2000;161:A888. (Abst)

83. Kavuru MS, Sullivan EJ, Piccin R, Thomassen MJ, Stoller JK. Exogenous granulocyte-macrophage colony-stimulating factor administration for pulmonary alveolar proteinosis. Am J Respir Crit Care Med 2000;161:1143-8.

84. Yokomura K, Chida K, Suda T, et al. [Secondary pulmonary alveolar proteinosis associated with myelodysplastic syndrome.] Nihon Kokyuki Gakkai Zasshi 2002;40:599-604.

85. Wardwell NR Jr, Miller R, Ware LB. Pulmonary alveolar proteinosis associated with a disease-modifying antirheumatoid arthritis drug. Respirology 2006;11:663-5.

86. Kosacka M, Dyla T, Jankowska R. [Alveolar proteinosis after professional exposure to cotton and linen dust, successfully treated with whole lung lavage - a case report] Pneumonol Alergol Pol 2004;72:217-20.

87. Kazkaz H, Isenberg D. Anti B cell therapy (rituximab) in the treatment of autoimmune diseases. Curr Opin Pharmacol 2004;4:398-402.

88. Huffman JA, Hull WM, Dranoff G, Mulligan RC, Whitsett JA. Pulmonary epithelial cell expression of GM-CSF corrects the alveolar proteinosis in GM-CSF-deficient mice. J Clin Invest 1996;97:649-55. 


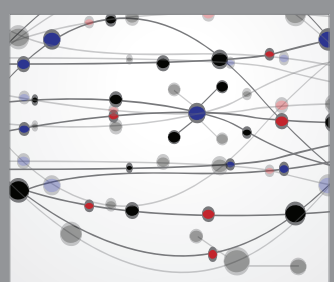

The Scientific World Journal
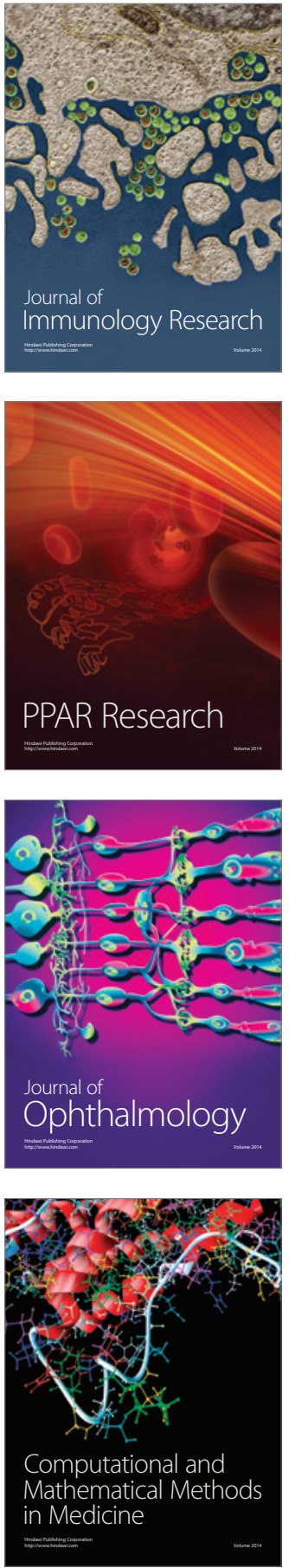

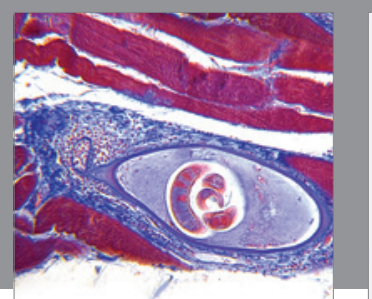

Gastroenterology Research and Practice

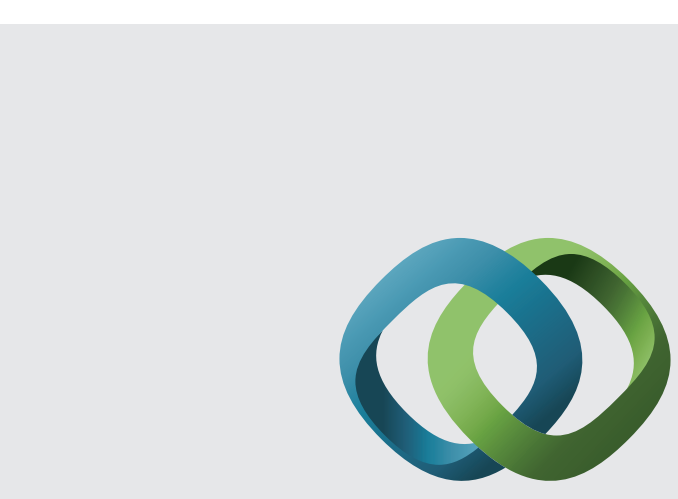

\section{Hindawi}

Submit your manuscripts at

http://www.hindawi.com
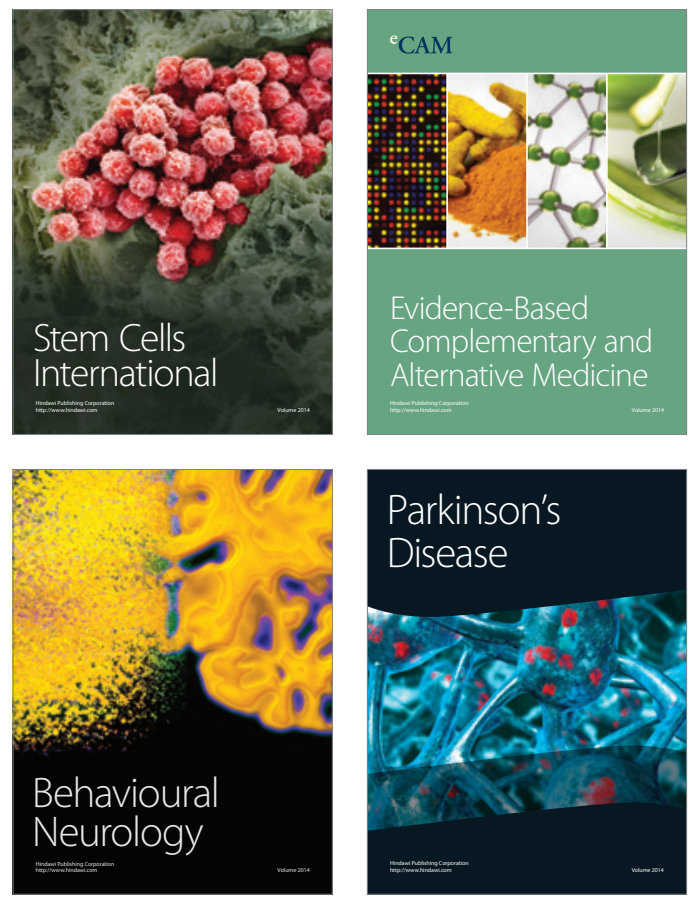
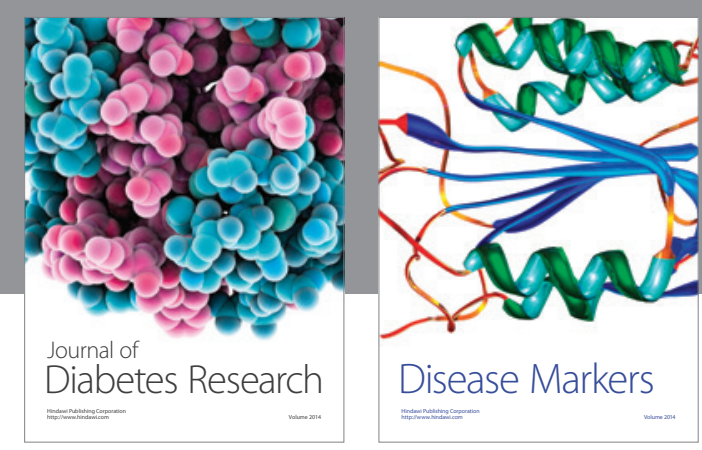

Disease Markers
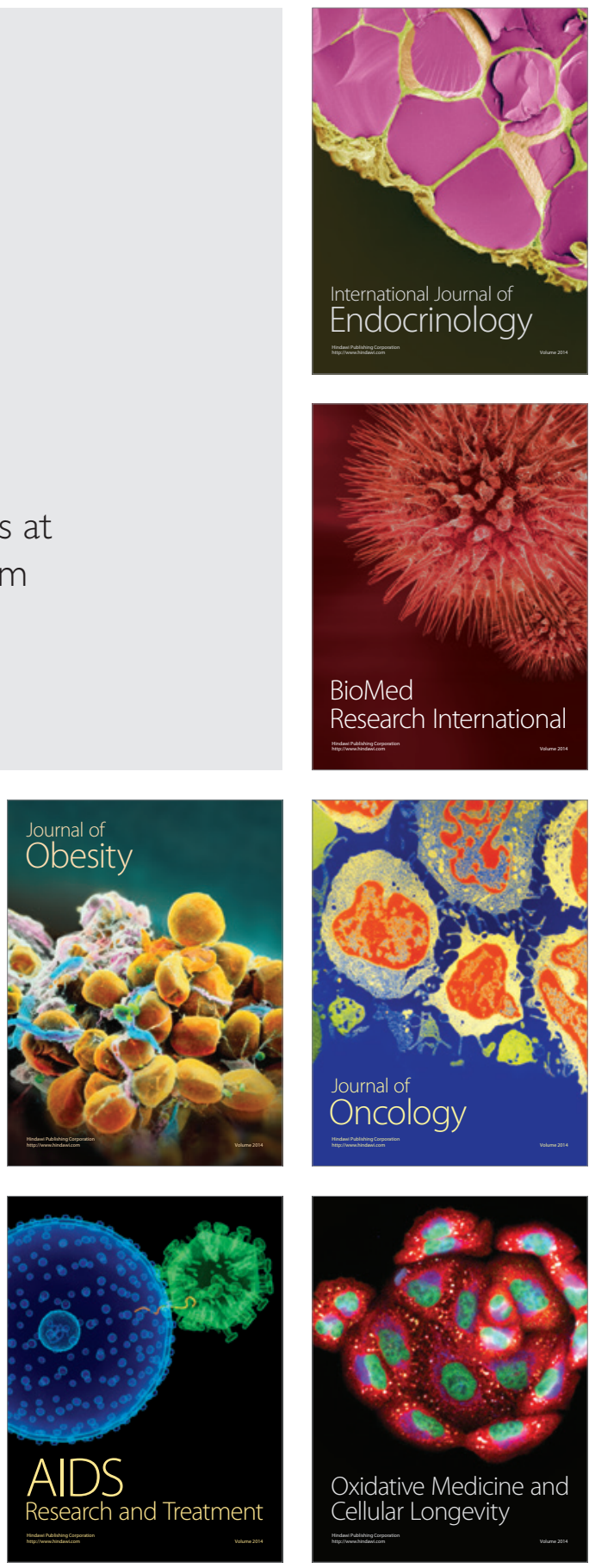